\title{
ЭКСТРАПОЛИРУЯ ЭЙНШТЕЙНА И ВИНЕРА
}

\author{
/In the footsteps of Einstein and Wiener/
}

I

В любые времена и эпохи наука развивалась, как правило, в двух направлениях: интегративном и редукционистском. Оба этих, казалось бы, взаимоисключающих вектора, по сути дела, реализуют, да и в дальнейшем будут определять (причем вне зависимости даже от нашего собственного желания) пути развития всего интеллектуального земного сообщества. Но вот появляется вдруг весьма неожиданное исследование, в котором эти векторы творчески переплетаются, выдавая в итоге на-гора нечто из ряда вон выходящее!..

Именно с таких позиций можно, судя по всему, рассматривать выход в свет небезызвестных книг «Синергетика» Г.Хакена, «Математическая теория связи» К.Шеннона, «Философрия и компьютинг» Л.Флориди, «Доказательство симуляции» Н.Бострома. Хотя, как впоследствии выяснилось, у всех у них были, оказывается, куда более достойные и прозорливые предшественники на востоке (Ex oriente lux. - Sic!). Прежде всего это, конечно же, легендарный создатель тектологии А.А.Богданов-Малиновский, пионер-разработчик советских релейно-контактных схем В.И.Шестаков, видный отечественный космоглобалист А.Д.Урсул. Так, скажем, именно вице-президент Молдавской академии наук Аркадий Урсул смог сорормулировать необходимый кибернетический критерий эволюционного развития, а также выдвинул прогрессивную гипотезу о роли инорормации в ускорении развития материи вообще и социального прогресса в частности.

Что ж до столь популярной нынче компьютерно-симулятивной теории, то она впервые зародилась отнюдь не в туманной Скандинавии, а в трудах современного украинского естествоиспытателя Ю.Н.Тесли.

Вы заинтригованы таким неожиданно шустрым началом? Тогда смеем вас заверить, что в данном мультидисциплинарном исследовании на суд читательской публики будет вынесена не одна, а ровно 5 свежих новаторских идей, способных перевернуть общепринятые научные устои в буквальном смысле этого слова с ног на голову. И причем везде по мере возможностей приводимые тут авторские аргументы дополняются, как и положено в подобных случаях, также и конкретными фризико-математическими выкладками, ну или соответствующими уравнениями.

\section{II.}

Что такое инорормация? Последние 100 лет этот бесхитростный с виду вопрос упорно будоражит многие ученые умы, приведя в итоге к появлению самых разнообразных и даже экзотических подчас взглядов на ее природу, законы и свойства. Хотя условно все эти теории можно всё же разбить на два принципиальных кластера. Причем к первому из них (наиболее раннему) относятся те фрормулировки, в которых информация рассматривалась как некая прикладная ипостась повседневной человеческой жизни. Именно такой точки зрения придерживался, между прочим, и Н.Винер, определяя её как «некое содержимое, получаемое нами из внешнего мира в процессе приспосабливания к нему наших чувств». Однако сейчас уже большинство теоретиков поневоле (вслед - отмечу - за 
А.Д.Урсулом и Л.Флориди) пришли в конце концов к мысли, что информация представляет собой вполне объективную категорию, присущую любому материальному телу, а не только одушевленному. Это и есть второй, более зрелый этап поступательного семантического развития данного термина. Хотя вместе с тем все подобные выводы базируются на понимании информации как меры упорядоченности. А сама упорядоченность, в свою очередь, создается направленной деятельностью человека, робота или же - на элементарном уровне - неких реально (на мой взгляд) существующих либо виртуальных (в концепции профр. Юрия Тесли) «инорормонов». Причем все инфрормоны обязательно а priori должны обладать кратковременной памятью, которую в ходе эволюции научились (разумеется, при помощи уже иных, более массивных и зримо замечаемых частиц) переводить в долговременную. Таким образом, любая информация - даже человеческая или компьютерная (представленная уже здесь в интегрированном своем виде) - создается именно инорормонами (но, правда, в альтернативной «теслевской» трактовке они выступают всего лишь в роли ее служебных переносчиков).

Что же касается пресловутого многоликого хаоса, то тут мнение ученого сообщества и вовсе диаметрально разделилось: если большинство «технарей» (ссылаясь на первый и второй законы термодинамики) считают его активно действующим фрактором, то вот как раз уже их антиподыгуманитарии, проводя зримую аналогию с костлявой распатланной смертью (которая если где-либо и существует, то разве что в чьем-то болезненном воображении или же на устрашающих картинках из старой церковной литературы) явно уж склонны причислять его к чисто резидуальным френоменам, свидетельствующим попросту об отсутствии порядка. Однако, как бы там ни было, любые целенаправленные действия человека заведомо - хоть на йоту, хоть на бит - уменьшают вселенскую энтропию. То есть каждое, по сути, рукотворное изменение в природе создает некий счетный инорормационный продукт (пускай, возможно, и столь же неуловимо малый, как Планковский квант времени) отдаляя тем самым нас и от злополучного «конца света». Более подробно об этом мы еще расскажем в заключительном разделе данной статьи.

\section{III.}

Согласно общепринятой версии, всё в мире началось с единого сгустка праматерии-праэнергии, обладавшего нулевой информацией. Сегодня же остаточная энергия явно находится в подчинении Высшей Воли (хотя, по большому счёту, между ними вполне возможны и другие субординационные связи). Вместе с тем сама по себе она всё же, очевидно, не способна создавать новую инорормацию (но, впрочем, не исключено, что умеет зато при этом поглощать уже готовую - с целью последующей ее переработки в энергию).

А вообще можно, по идее, представить себе три принципиальных динамических схемы мироздания:

а) своеобразные качели «от энергии (Воли) $\Rightarrow$ к инорормации (Разуму) и обратно»;

б) непрерывные эксперименты или даже экспромты самой Воли (сюда же, кстати, вписывается и хорошо, видимо, многим известное теософское откровение о бытовавших прежде 5-и бесплотных расах). 
в) ну и наконец, как бы независимо от них здесь может быть рассмотрена также и вышеупомянутая гипотеза о нашем бытии как компьютерной симуляции фризического мира (причем в этом случае столь привычные для «айтишников» биты и байты перейдут уже в ранг главного источника взаимодействия всех его реально-виртуальных объектов).

Что касается Высшего Разума, то для него (в отличие от чётких канонов христианской троицы), пока еще не разработано определений типа «информация-мать»* (которая, в принципе, должна быть тождественна вселенской ноосорере), «порядок-сын» или же «негэнтропия святая». И даже существование в мире «скорострельных» мнемофокусников (Юрий Горный, Андрей Слюсарчук, Шакунтала Дэви), как, впрочем, и френоменальных предсказателей (Мишель Нострадамус, Эдгар Кейси, Вангелия Гущерова) не является, увы, сколь-нибудь весомым и убедительным аргументом в смысле их причастности к подобной плеяде «порядочных сыновей». Ибо альтернативная версия (связанная с использованием пока еще скрытых для нас мозговых ресурсов) выглядит в данном случае более естественной. Хотя, с другой стороны, тот вполне очевидный фракт, что именно рассеянной повсюду негэнтропии (а точнее - ее элементарным носителям) принадлежит решающая роль в планетарном и технологическом прогрессе, воспринимается сейчас уже, по сути, как бесспорная азбучная истина.

В естественных (т.е. созданных самою природой) объектах инорормация - в виде, скажем, зачаточной кратковременной памяти способна какой-то период циркулировать внутри замкнутых органических колец. А уж тем более, если такие кольца скомпонованы (как, например, в структуре полинуклеотидов) одно под другим в трехмерную идеально выстроенную цепочку - то это, судя по всему, дает уже нам серьёзные основания предположить у них наличие и неких элементов психики. Не говоря уж о простейших полупроводниковых триодах, обрабатывающих по заданному алгоритму экстериорный, т.е. явно привнесенный свыше генетический код.

Поскольку как информация, так и самоорганизация имеют прямое отношение к упорядоченности, то, очевидно, это звенья одного общего вселенского процесса. С той лишь условной разницей (на уровне, скорее, обыденной терминологии), что инфрормоны появились сразу же после Большого Взрыва, тогда как о реальной самоорганизации можно вести речь только, пожалуй, с появлением у них новых вспомогательных атрибутов, связанных с долговременной памятью.

Вот почему известный в науке тезис, что «Вселенная упорядочивается в качественном (т.е. более существенном и важном) отношении, разупорядочиваясь в то же время в количественном (тепловая энтропия)» должен быть, по-видимому, распространен на все классические законы термодинамики (и в частности, второй). Впрочем, то же самое касается и синергетики - вопреки тому, что представлял себе И.Пригожин (т.е. якобы отдельные фрлуктуации возникают на фроне общего увеличения энтропии, но всё это лишь в каком-то ограниченном пространстве).

То есть, скорее всего, разупорядочивание идет по энергетическому вектору, а упорядочивание - по инорормационному. Но эта зависимость не носит, однако же, линейного характера, поскольку развитый интеллект создаёт новую алгоритмическую продукцию намного проще и быстрее - без высоких энергозатрат (если сравнивать с тем, что было на заре становления Вселенной). А значит, и почти уже теряет смысл дилемма насчет того, «чем 
именно порождаются нынешние алгоритмы: самоорганизацией или интеллектом», так как любой современный интеллект, в свою очередь, есть продукт самоорганизации. Практически все существующие сегодня законы фризики, химии и биологии (а особенно - первые из них) являются результатом действия самоорганизационных процессов, ибо все они, так или иначе, связаны с движением.

Кстати, проректор столичного университета гражданской авиации «НАУ» Ю.Н.Тесля в одной из своих недавних монографий предложил следующую фрормулу, сопоставляющую скорость движущегося фризического тела с его инорормационным контентом:

$$
\vec{V}=(2 \cdot p-1) \cdot \vec{c}=\frac{d}{i} \cdot \vec{c}
$$

где $\vec{c}$ - скорость света в вакууме; $\vec{V}$ - скорость дрейора самого исследуемого объекта; $p$ - вероятность смещения данного объекта на 1 квант пространства за 1 квант времени; $d$ - количественная предопреленность подобного движения; і- общая инорормированность объекта о потенциальных динамических возможностях (для каждого конкретного случая).

Возвращаясь же попутно к нашей стержневой идее, отнюдь не зря вынесенной в заголовок настоящей статьи, отметим, что эта фрормула тоже по-своему (а главное - весьма удачно) экстраполирует специальную теорию относительности А.Эйнштейна в современном научном пространстве Н.Винера. Потому как самым непосредственным образом базируется на информационно-вероятностной интерпретации механического движения.

То есть, если досконально в этом разобраться, то согласно выводам Юрия Николаевича, в природе есть нечто, воспринимаемое нами под личиной пространственно-временной зависимости, всемирного тяготения, электромагнетизма, слабых и сильных ядерных взаимодействий. Однако на практике все эти видимые (хотя зачастую и обманчивые) эфрфректы реализуются через соответствующие инфо-поля. Иными словами, если какоелибо $N$-ное поле существует, значит, где-то должен быть и создающий его объект, - что, по логике проф. Тесли, является уже некой актуальной/ инорормацией для других соседних с ним объектов. В этой связи хотелось бы привести тут еще одну довольно-таки любопытную и смелую цитату из его свежайших опубликованных работ: «Движение любых природных тел определяется их инфрормационным содержанием, т.е. сложившимися за 13,8 миллиардов лет навыками правильно реагировать на бытие других своих соседей. Особенно если учесть, что за столь широкий промежуток времени наверняка успел уже сфрормироваться более чем достаточный по объёму кластер полезных для них рефолексов» **.

\section{IV.}

Как известно, порядок и упорядочивание это две различных фрилософских категории. Первая из них определена конечным набором структурных компонентов в пост-сингулярной фразе. А вторая - наличием во Вселенной неких мельчайших и безотказных «супер-трудяг», постоянно задействованных в наращивании везде вокруг себя процентной доли порядка. Главным же фрункциональным достоинством этих микроагентов является наличие у них памяти. Впрочем, поскольку речь тут пока идет об обычных элементарных частицах, то до обладания подлинно конструктивными или созидательными способностями им, разумеется, еще очень далеко: какие-то 
начальные творческие проблески (не говоря уж о планировании) могут проявиться разве что при их сплочении в ограниченном пространстве. Да и то - лишь под влиянием постороннего фрактора, ибо сами организоваться в подобную систему они заведомо не сумеют.

В этом контексте модный нынче, но весьма, однако же, спорный «закон неуничтожимости инорормации» правильнее, видимо, было бы сорормулировать так: готовый интеллектуальный продукт (созданный будь то человеческим сообществом, надорганизменным менталом или даже отдельными инорормонами) автосохранению, увы, не подлежит. А вот уже насколько долго могут сберегаться удачные мимолетные образы или даже бесценные авторские ноу-хау в памяти самих творцов такого продукта - это достаточно сложный вопрос, решаемый каждый раз по-разному.

Что же касается другого не менее актуального для нас свойства информации - практически ничем не лимитированной копируемости, - то оно, по идее, должно обусловливаться соответствующими характеристиками ее элементарных носителей, а именно - либо самоудвоением, либо бесконтактной передачей тех или иных внутренних параметров. И в этом как раз состоит основное отличие таких мобильных и гармоничных микрочастиц от «духа святого», который (если даже, например, уподобить его некоему калибровочному полю) зиждется на абсолютно инертных и невесомых, но зато уж вечных и поистине всепроникающих «волюнтонах». Ну и, кроме того, отнюдь не исключено, что презентуемая нам свыше энергия, как и вселенское время, вообще не подлежит разбивке на мельчайшие дискретные компоненты, так как де-фракто представляет собой атрибут, а не субъект прогрессивного эволюционного развития (или, если угодно, взаимодействия между различными видами материи).

Кстати, кажущаяся со стороны полярность интересов Разума и Воли на самом деле иногда ощущается разве что, пожалуй, в социальноисторической плоскости. В остальном же они повсюду идут рядом, как бы взаимодополняя друг друга, причем под общим верховенством (пока, во всяком случае) именно Разума. Поэтому противопоставлять их в масштабах Вселенной можно (да и то - лишь как одну из допустимых опций) только по временным параметрам: от энергии насыщенного, но бесструктурного хаоса к предельно структурированному, но холодно-безжизненному Космосу. И как раз на этом фринишном отрезке из-за критической нехватки природных ресурсов действительно представляется вполне уже реальным энергозависимый переход к гегемонии роботов.

\section{V.}

Поскольку инорормация и энергия имеют в своей родословной совместную начальную точку - то, значит, между ними отнюдь не исключены и некоторые сами собой напрашивающиеся параллели. Так, например, по аналогии с классической фрормулой Эйнштейна: $E=m c^{2}$ (связывающей массу покоя с энергией), можно, видимо, составить похожее равенство и для нужд синергетики. Однако же при этом следует, бесспорно, принять во внимание, что при одинаковом весе 6-тонная куча навоза, африканский слон и коллектив научно-проектного института будут иметь совершенно разные инорормационные показатели (не говоря уж об индексах цитирования). Более того, даже сам вышеупомянутый слон может быть как живым, так и дохлым; а 
институт располагаться как на территории цивилизованной Европы, так и среди диких папуасских джунглей (с соответствующим IQ его сотрудников). Вот почему вместо обычной массы мы в данном случае должны оперировать прежде всего скрытой (dark matter) - учитывая притом заодно, что из пяти известных на сегодня теософских оболочек, как минимум, 90\% инорормации сосредоточено именно на уровне ментала и «духа» (каркаса).

Впрочем, произвести подсчет этой почти неуловимой на глаз материи, несмотря на кажущуюся проблематичность, по идее, не составляет особого труда: достаточно всего лишь из общего веса человека вычесть «львиную долю» входящих в него нуклонов. Хотя, кстати, здесь есть и еще один запасной метод, заключающийся в длительном (двух- или даже трехсуточном) кропотливом наблюдении за умирающими людьми, от которых, в принципе, тоже как раз должны поочередно отделяться интересующие нас тонкие посмертные сущности.

Далее, вместо скорости света ставим, разумеется, скорость распространения гипотетических инорормонов в вакууме.

Ну и наконец, самая, пожалуй, сложная часть задачи, связанная с малозаметным, но ключевым по своей роли надстрочным знаком. Ведь несмотря на то, что уровень организации материи обязательно, вроде бы, должен тут присутствовать, однако в каком именно виде (коэфроициента, степени, натурального логарифма или, возможно даже, фракториала) - не совсем, увы, пока еще понятно. Кроме того, остается открытым и вопрос, учитывать ли межсистемные уровни (атом - молекула - нуклеотид - ген клетка - семья - государство и т.д.) как самостоятельные или же ограничиться лишь пятью основными, «жизнеподобными».

Итак, предварительная фрормула имманентной (синонимы: внутренней, априорной) присущей данному физическому телу инфрормации могла бы вчерне выглядеть следующим образом:

$$
I_{(p)}=\left(M_{(d)} K\right)^{L}
$$

(где $L$ - положительное целое число, которое на практике, т.е. без учета бесконечной фррактальной делимости в духе Анаксагора, никак не может быть больше, чем 15; так что надстрочный символ "L" не имеет в данном контексте никакого отношения к логарифму: это просто сокращение от английского "level").

Если же теперь перейти к долговременной человеческой памяти - как главному вместилищу всей приобретенной и новосозданной информации, - то тут прежде всего стоило б, очевидно, выяснить, по какой именно системе: двоичной (как у роботов) или, скажем, более знакомой нам десятеричной - она записывается в мозговых структурах. Кстати, в первом случае сумму активных мнемо-битов было б, наверное, куда легче подсчитать - например, по общему количеству значимых дуальных «перемычек» в здешних белковых молекулах. Учитывая, правда, и то, что отнюдь не все внутрипептидные связи могут выполнять эту роль. В частности, центровой углеродный остов и напрямую соединенную с ним карбоксильную группу следует, пожалуй, признать творчески инертным органическим фрундаментом, а вот аминопирамиду и разветвленный боковой радикал - как раз уже непосредственно интересующими нас носителями памяти.

Почти тем же способом определяется и мощность мышления; но с обязательным учетом, кроме того, и многоярусности «серого вещества», благодаря которой совокупное число возможных релейных перемычек 
экспоненциально в итоге увеличивается. И причем как внутри самих полушарных модулей, так и между отдельными звеньями нео- и палеокортекса.

Тем не менее следовало бы всё же подчеркнуть, что конвертировать информацию в энергию для современного человечества представляется (ну, по крайней мере, на данном этапе его развития) абсолютно нереальной сверхфантастической задачей. И даже общая их точка отсчета вряд ли тут каким-то образом поможет: ведь хотя по своей родословной это и «родные сестры», но совсем, увы, не близнецы. Так что внешняя схожесть отдельных законов развития еще ни о чем не говорит!..

\section{VI.}

Диковинные артефакты на снимках, сделанных в кромешной темноте (но с ручной выдержкой), голоса Раудива, «модулированные шумы» братьев Ламоро, а также некоторые небесные и особенно уорологические знамения вполне могут свидетельствовать или о не совсем правильной трактовке нами информации (как универсального мультивселенского феномена в целом), или о том, что мы осознаем и воспринимаем ее через посредство собственных тонких оболочек, т.е. в извращенном виде. При этом наиболее заметная роль в объяснении подобных парадоксов принадлежит, пожалуй, двум современным американским исследователям Дж. Аллену Хайнеку и Жаку Валлё, представивших на суд мирового ученого сообщества свою альтернативную гипотезу «еxtradimensional intelligence» (аббр. - EDI). B частности, именно благодаря их неугомонной творческой позиции и энтузиазму, где-то уже на исходе минувшего столетия удалось-таки прочно внедрить в повседневный научный обиход такие востребованные нынче термины, как сенсорный орильтр, иноросубъективизм, «the multiverse», параллельные миры. Впрочем, как впоследствии выяснилось, еще даже сам отец кибернетики Норберт Винер маялся подспудными сомнениями в чёткой_ детерминированности инорормации, подразумевая под нею (в отличие от простоватого и бесхитростного инженера-дешифровщика Шеннона), достаточно расплывчатые сведения, которые любой активно воспринимающий субъект способен интерпретировать по-своему.

Но вместе с тем, несмотря на кажущуюся умозрительность данного понятия, у него наверняка всё же должно быть конкретное материальное обоснование (хотя бы в виде каких-то неуловимых пока квазичастиц или калибровочного поля): ведь иначе здесь можно вообще дофилософствоваться в итоге до пустопорожней софистики и агностицизма. Так что именно с этой целью обратимся теперь к закону перемежающегося подобия*** и вспомним, что непосредственным иерархическим предком любого многоклеточного организма является свободный тепловой нейтрон, изрядно, увы, ограниченный в сроках своей жизнедеятельности - как, к сожалению, и сам даже нынешний «повелитель природы» Homo sapiens. Живёт он в среднем 880,1 \pm 1,1 сек., после чего распадается, как правило, на три отнюдь не равнозначных компоненты. Но поскольку временами тут могут наблюдаться и другие эксклюзивные случаи, то лучше уж зримо представить всё это в виде триады спаренных фрормул. Спаренных же потому, что рядом с каждым тривиальным квантово-механическим уравнением заодно будет 
указана и его спроецированная, так сказать, на нашу с вами действительность макро-аналогия.

a) $\beta^{1}\left(n \rightarrow p+e^{-}+\bar{y}_{e}\right)$

$\mathrm{LC} \rightarrow \mathrm{s} / \mathrm{d}+\mathrm{s}^{\mathrm{v}}+\mathrm{s}^{\mathrm{m}}$

Это обыденный, т.е. самый распространенный вариант кончины, при котором бывший живой организм (living creature) распадается на труп (subject for dissection), вегетативное лептонное покрывало (vegetative sheath) и остаточный микролептонный образ (mental sheath).

б) $\beta^{2}\left(n \rightarrow p+e^{-}+\bar{\psi}_{e}+y\right)$

$$
\mathrm{LC} \rightarrow \mathrm{s} / \mathrm{d}+\mathrm{s}^{v}+\mathrm{s}^{\mathrm{m}}+\mathrm{s} / \mathrm{s}
$$

А вот это уже более редкий феномен - с дополнительным выделением плюс к тому же и невесомой сияющей субстанции (shining substance). Причем, по всей видимости, так способны уходить из жизни лишь некие особо «просветленные» гуру, пророки и чудотворцы.

в) $\beta^{3}\left(n \rightarrow{ }^{1} \mathrm{H}+\bar{\psi}_{\mathrm{e}}\right)$

$\mathrm{LC} \rightarrow \mathrm{hr}+\mathrm{s}^{\mathrm{m}}$

А это и вовсе редчайшее, поистине уникальное природное явление, в результате которого образуются нетленные мощи (the holy relics), т.е. тело пока еще сохраняет какие-то свои вегетативные функции, хотя сам человек уже мертв.

\section{VII.}

Итак, время теперь подвести обобщающую черту, то есть, попросту говоря - ответить на вопрос, какие же полезные для академической науки выводы и умозаключения могли бы, в принципе, отсюда последовать.

Ну, прежде всего - то, что единственными переносчиками (а возможно даже, и первородными творцами) инорормации способны, очевидно, быть лишь поразительно вездесущие, энергичные и неутомимые работяги-лептоны. Причем данный вердикт - вполне конкретный, чёткий, бесповоротный и обжалованию уже, как говорится, не подлежит. Ибо, какой бы глобальной парадигмы мы тут ни придерживались, но и в расширенной («теслевской») формулировке, и в традиционной всё по-настоящему ценное_и содержательное для любой природной системы несут в себе лишь мельчайшие электронно-нейтринные ансамбли. Например, при механическом движении элементарных частиц именно они способны определять его направленность (на основании чего Ю.Н.Тесля как раз и настаивает на их сугубо калибровочном характере).

Во-вторых, воскрешение умерших - и притом как в новосозданном теле, так и в изжившем даже, казалось бы, уже себя старом (что порой обнаруживается при эксгумации покойников) - на поверку, выходит, и впрямьтаки существует. Более того, в современной ядерной физике подобный процесс (обратный, кстати, по отношению ко всем трем вышерассмотренным опциям) тоже, в принципе, хорошо и давно уже изучен, именуясь, к слову, понаучному е-захватом. Детальней это описано в свежайшем научнопопулярном трёхтомнике директора столичного Института искусственного интеллекта, чл.-корр. НАН Украины А.И.Шевченко «Путь к истине».

Ну и, кроме всего прочего, заодно как бы по ходу дела тут сразу вылазит на поверхность и множество иных чисто корпускулярных «нестыковок». Например, хотя бы вот такая. Как указано в любом вузовском 
учебнике по космологии, вследствие Большого Взрыва в некоем ограниченном пространстве образовалось почти равное количество известных ныне элементарных частиц, в том числе протонов, нейтронов, антипротонов, электронов, позитронов и т.д. Однако после аннигиляции вещества с антивеществом львиная доля из них взаимоуничтожилась, дав тем самым толчок так называемому реликтовому излучению. И далее (причем в том же самом учебнике) через несколько страниц читаем: общее количество нейтронов составляет сейчас во Вселенной примерно $15 \%$ от соответствующего числа протонов. Помилуйте - но как такое возможно: ведь они же (будучи per definitionem нейтральными) ни с кем при этом в реакцию не вступали, - а значит, всё, скорее уж, должно быть с точностью до наоборот!.. То есть, получается, лишь авторская теория спироэманогенеза способна предложить тут достаточно внятное непротиворечивое обоснование: ведь, по сути дела, большая часть инертной протоновой материи являет собою просто-напросто элементарную свалку (или, если угодно, скопление трупов) от былой нейтронной жизнедеятельности. Ибо в фремтомире, как известно, отсутствуют свои бактерии или грибы, которые бы умели разлагать падаль.

Однако, как и в любой новаторской концепции, не обошлось здесь, увы, и без некоторых темных пятен. И самое очевидное из них связано в основном с адекватной трактовкой столь загадочных и воистину неуловимых «волюнтонов». Так что остается пока тешить свое самолюбие, пожалуй, лишь тем, что данный философский вопрос явно уже выходит за пределы информатики. А впрочем, это как раз, с другой стороны, также и означает, что ему наверняка уж нужно будет уделить куда более пристальное внимание в дальнейших наших публикациях!..

- Хотя вместе с тем компьютерно-симулятивная теория как раз и утверждает, что подобного рода «информация-мать» заведомо должна в нашем мире присутствовать!

** Под рефлексами здесь следует подразумевать целостное реагирование данного конкретного объекта на информацию, поступающую к нему извне.

*** См. по этому поводу предыдущую авторскую статью «Трудноразрешимые парадоксы эволюции - всеохватывающим взором натурфилософа»: https://doi.org/10.24108/preprints-3112160 